\title{
TEMÁTICA DEFICIÊNCIA EM GRUPOS DE PESQUISA EM PSICOLOGIA DO CNPQ
}

\author{
TEMA DE LA DISCAPACIDAD EN LOS GRUPOS DE INVESTIGACIÓN EN \\ PSICOLOGÍA DEL CNPQ
}

THE DISABILITY THEME IN CNPQ PSYCHOLOGY RESEARCH GROUPS

\author{
Raíssa Matos FERREIRA ${ }^{1}$ \\ Adélia Augusta Souto de OLIVEIRA ${ }^{2}$
}

RESUMO: Este artigo teve como objetivo mapear a produção científica de pesquisadores da área da Psicologia que investigam a deficiência no Brasil. Foi realizada uma metassíntese de 40 artigos, de 3 grupos de pesquisa, do Diretório dos Grupos de Pesquisa e Currículo Lattes. Os grupos de pesquisa estão localizados na região Sudeste, sendo 2 deles vinculados à Universidade de São Paulo (USP), criados em 2002, e o outro, à Universidade Estadual Paulista Júlio de Mesquita Filho (Unesp), criado em 2012. Os resultados indicam a presença das perspectivas teóricas Winnicottiana, Sócio-Histórica, Histórico-Cultural e das Representações Sociais, das concepções de deficiência, Educação Especial/Inclusiva, acessibilidade e empregabilidade, de documentos nacionais e internacionais de garantia de direitos e do uso do método qualitativo, com a participação de crianças e adultos. Conclui-se que as produções estabelecem interlocuções entre as áreas da Psicologia e Educação, e contribuem nas discussões sobre a inclusão da pessoa com deficiência.

PALAVRAS-ChAVE: Deficiência. Diretório dos grupos de pesquisa. Currículo lattes. Psicologia. Metassíntese.

RESUMEN: Este artículo tuvo como objetivo mapear uma producción científica de investigadores en el campo de la Psicologia que investigan la discapacidad em Brasil. Se realizó una metasíntesis de 40 artículos, de 3 grupos de investigación, del Directorio de Grupos de Investigación y Currículo Lattes. Los grupos de investigación están ubicados en la región Sudeste, 2 de los cuales están vinculados a la Universidad de São Paulo (USP), creada en 2002, y el otro a la Universidade Estadual Paulista Júlio de Mesquita Filho (Unesp), creada en 2012. Los resultados indican la presencia de perspectivas teóricas Winnicottiana, sociohistórica, histórico-culturale y representaciones sociales, los conceptos de discapacidad, Educación Especial/Inclusiva, accesibilidad y empleabilidade, documentos nacionales e internacionales y el uso del método cualitativo, con la participación de niños y adultos. Se concluye que las producciones estabelecen interlocuciones entre las áreas de Psicología y Educación, y contribuyen las funciones de inclusión de personas con discapacidad.

\footnotetext{
${ }^{1}$ Universidade Federal de Alagoas (UFAL), Maceió - AL - Brasil. Doutoranda no Programa de Pós-Graduação em Educação. ORCID: https://orcid.org/0000-0003-3421-2899. E-mail: raissa.ferreira@cedu.ufal.br

${ }^{2}$ Universidade Federal de Alagoas (UFAL), Maceió - AL - Brasil. Docente no Programa de Pós-Graduação em Psicologia. Doutorado em Psicologia Social (PUC-SP). ORCID: https://orcid.org/0000-0001-5635-1510. E-mail: adeliasouto@ip.ufal.br
} 
PALABRAS CLAVE: Discapacidad. Directorio de grupos de investigación. Currículo lattes. Psicología. Metasíntesis.

ABSTRACT: This study aimed to map the scientific production of researches in field of Psychology who investigate disability in Brazil. A metasynthesis of 40 published articles was carried out of 3 groups of the Directory of Research Groups and Curriculum Lattes. The 3 research groups are located in the Southeast region, 2 of which are linked to the University of São Paulo (USP), created in 2002, and another to Universidade Estadual Paulista Júlio de Mesquita Filho (Unesp), created in 2012. The results of the analysis indicate the presence of the Winnicottian, Socio-Historical, Historical-Cultural and Social Representations theoretical perspectives, of the concepts of disability, Special and Inclusive Education, accessibility and employability; national and international rights guarantee documents and the use of the qualitative method, with the participation of children and adults. It concludes that the establish interlocutions between the areas of Psychology and Education, and contribute in the discussions about inclusion of the person with disability.

KEYWORDS: Disability. Research groups directory. Lattes curriculum. Psychology. Metasynthesis.

\section{Introdução}

Este artigo trata da temática deficiência. No contexto brasileiro, acompanhou-se a ampliação e promoção dos direitos das pessoas com deficiência, por meio de implementação de políticas públicas, de aprovação de leis, de realização de convenções e conferências. Nesse sentido, Silva Júnior (2016) relata que as modificações paradigmáticas, que ocorreram nas últimas décadas, resultam da luta dos movimentos sociais, profissionais e pesquisadores de diversas áreas de conhecimento, que se opõem ao processo de exclusão das pessoas com deficiência.

Ressalta-se que o Modelo Social da Deficiência ganhou força, segundo Guadenze e Ortega (2016) na década de 1980, em contraposição ao Modelo Médico da Deficiência. Além disso, reiteram o avanço legítimo da Classificação Internacional de Funcionalidade, Deficiência e Saúde (CIF) da Organização Mundial de Saúde (OMS) em 2001, pois o Modelo Social da Deficiência transcendeu de uma categoria considerada, apenas, biomédica na Classificação Internacional de Lesão, Deficiência e Handicap (ICIDH), sugerida pela Organização Mundial da Saúde em 1980, para um cunho também sociológico e político.

Ademais, as lutas empreendidas nas Conferências Nacionais sobre os Direitos das Pessoas com Deficiência, que ocorreram nos anos 2006, 2008, 2012 e 2016, realizadas em Brasília, as quais contribuíram de modo significativo, no debate sobre a pessoa com deficiência. Vale pontuar ainda, nessa dimensão, a promulgação do decreto $n^{\circ} 6.949$, de 25 de agosto de 
2009, a Convenção Internacional sobre os Direitos das Pessoas com Deficiência e seu Protocolo Facultativo, assinados em Nova Iorque, em 30 de março de 2007 (BRASIL, 2012).

Bezerra (2017) ressalta que a inclusão se configurou como um importante avanço na educação brasileira, que se deu por meio da implementação da Política Nacional de Educação Especial na Perspectiva da Educação Inclusiva, lançada pelo Ministério da Educação (MEC), em 2008 (BRASIL, 2008). Nessa direção, o autor propõe uma mudança paradigmática, no modo de entender a participação dos alunos da Educação Especial inseridos, no ensino regular, ou seja, de uma perspectiva integradora a um modelo inclusivo. Desse modo, apresentaria o objetivo de garantir o acesso do ensino regular, visando à transversalidade da modalidade de educação especial, desde a educação infantil até a educação superior, por meio de atendimentos especializados, com formação de professores com base em acessibilidades e a inclusão da participação da família e da comunidade.

Recentemente, em termos normativos, tem-se o Estatuto da Pessoa com Deficiência, que destaca que a Lei $n^{\circ}$ 13.146, promulgada em 6 de julho de 2015, denominada Lei Brasileira de Inclusão da Pessoa com Deficiência, que se configura como um dos marcos político-legais atuais e, tem como base a Convenção sobre os Direitos das Pessoas com Deficiência. Esse regulamento reitera nos dispositivos, a necessidade de avaliação do tipo de deficiência dos sujeitos, por meio de uma avaliação biopsicossocial, junto às equipes multiprofissionais e interdisciplinares. Diante disso, se ressalta a importância da participação de psicólogos nessas equipes (BRASIL, 2015).

Em consequência a essas conquistas, como a acessibilidade, nomenclatura diretamente relacionada às pessoas com deficiência, que trazem consigo acesso aos bens físicos e imateriais visando melhores condições para a qualidade de vida, Gomes, Rezende e Tortorelli (2010) citam a Lei $\mathrm{n}^{\circ} 10.048$, promulgada em 8 de dezembro de 2000 (BRASIL, 2000) que dá prioridade no que se refere à reserva de assentos preferenciais, assim como destacam a Lei ${ }^{\circ}$ 10.098, de 19 de dezembro de 2000 (BRASIL, 2000), que estabelece outras normas gerais e critérios relacionadas à supressão de barreiras e obstáculos nas vias e espaços públicos, no mobiliário urbano, na construção e reforma de edifícios e nos meios de transporte e de comunicação. As duas normas dispõem de prerrogativas fundamentais para a garantia do direito de acesso a essa parcela da população que necessita de ajustes para usufruir de espaços e se locomover em igualdade de condições com os demais.

No que se refere às interfaces entre a Psicologia e Educação, Guzzo et al. (2010), apresentam um panorama histórico que marcou o surgimento da Psicologia Escolar e Educacional no Brasil. Os autores destacam os fundamentos que subsidiam essa prática, 
reiterando a importância de refletir criticamente sobre o cenário político, social e econômico em que essa área da Psicologia se inseriu.

Nessa direção, pensar acerca da atuação de profissionais de Psicologia em contextos educativos e, mais especificamente, nos processos de inclusão e exclusão de pessoas com deficiência, faz-se necessário romper com práticas pautadas no paradigma centrado no modelo médico em que a avaliação de dificuldades de aprendizagem de crianças e jovens era realizada por meio de testes psicológicos, segmentando os considerados aptos e não aptos para a aprendizagem. Além disso, cabe refletir a importância de contextualizar e garantir a atuação desses profissionais nos diversos espaços educativos, considerando os saberes e as práticas de áreas afins para dialogarem acerca da realidade objetiva e subjetiva em que os sujeitos envolvidos nesses processos estão inseridos e, assim, construírem um movimento de transformação (GUZZO et al., 2010).

Ainda sobre isso, Guzzo e Ribeiro (2019, p. 300) destacam em relação à formação acadêmica, que "é preciso formar profissionais com uma leitura crítica da realidade brasileira, não apenas pelos estágios da universidade, mas pela experiência de trabalho cotidiano no campo educativo, a partir da inserção e presença cotidiana no campo". Nesse sentido, as autoras também enfatizam que cada vez mais tem-se publicado sobre a interlocução das áreas da Psicologia e Educação, principalmente, nos grupos de trabalho da Associação Nacional de Pesquisa e Pós-graduação em Psicologia (ANPEPP), que lutam constantemente para manter diálogos entre essas duas áreas, e deste modo, construírem práticas que visem romper com o modelo hegemônico e, assim, contribuírem no cotidiano escolar.

Diante disso, ressalta-se que quando se trata da temática deficiência, as transformações do campo de conhecimento da Psicologia a respeito podem ser acompanhadas na varredura da literatura. Nessa direção, considera-se pertinente conhecer o movimento histórico e social de grupos de pesquisa em Psicologia, os pesquisadores e suas produções publicadas acerca dessa temática, assim como as suas interlocuções com as áreas afins. Portanto, o presente estudo teve como questões norteadoras de pesquisa: Quais são os grupos de pesquisa em Psicologia do Diretório dos Grupos de Pesquisa no Brasil (DGP/CNPq) que investigam a deficiência? O que tem sido pesquisado acerca da temática deficiência no Brasil? Quais os aspectos temáticos, teóricos e metodológicos das produções publicadas pelos pesquisadores? Diante disso, apresentam-se, a seguir, os resultados do mapeamento de grupos de pesquisa em Psicologia e a metassíntese da temática deficiência, em artigos publicados pelos líderes pesquisadores de grupos de pesquisa em Psicologia do DGP/CNPq. 


\section{Método}

Para mapear o campo de conhecimento, optou-se pelo uso da metassíntese. Vosgerau e Romanowski (2014) apresentam a diversidade de métodos de revisão de literatura, e destacam que a expansão dos cursos de pós-graduação no Brasil, ocasionou um aumento de grupos de pesquisa, periódicos e eventos científicos. A diversidade de documentos (teses de doutorado, dissertações de mestrado e artigos científicos) e áreas de conhecimento é propícia à realização desses estudos.

Matheus (2009) ressalta que esse tipo de revisão qualitativa se diferencia das demais, em razão de sua síntese inovadora, ou seja, seu objetivo é gerar um novo conhecimento. Oliveira et al. (2015) apresentam diretrizes para a sistematização desse tipo de método, e ressaltam sua contribuição para o desenvolvimento da ciência. A metassíntese é realizada por meio de cinco fases: Exploração, Cruzamento, Refinamento, Descrição e Interpretação (OLIVEIRA; BASTOS, 2014; OLIVEIRA et al., 2015). As fases observam, concomitantemente, o conteúdo na perspectiva proposta por Bardin (2009): pré-análise, exploração do material, tratamento dos resultados e interpretações.

Em virtude disto, utilizou-se o Diretório dos Grupos de Pesquisa no Brasil (DGP/CNPq) para identificar os grupos de pesquisa ali cadastrados e a Plataforma Lattes para identificar a produção acadêmica dos líderes no formato de artigo. As buscas ocorreram entre os meses de julho e agosto do ano de 2017, no DGP/CNPq. O Conselho Nacional de Desenvolvimento Científico e Tecnológico (CNPq) foi criado em 1951 com o objetivo de promover e fomentar o desenvolvimento da ciência, tecnologia e inovação no Brasil. O DGP, por sua vez, surge em 1992, com o intuito de inventariar os grupos de pesquisa científica-tecnológica, em atividade em todo o país. Trata-se, portanto, de bases de dados virtuais de suma importância na divulgação das atividades científico-tecnológicas promovendo e contribuindo para o avanço da ciência no país.

$\mathrm{Na}$ primeira fase, exploraram-se, no DGP/CNPq, os Grupos de pesquisa com a utilização de seis descritores de busca:

Pessoa com deficiência, Pessoa com deficiências, Pessoas com deficiência, Pessoas com deficiências, Deficiência e Deficiências. O refinamento, realizado posteriormente, permitiu escolher os grupos que apresentavam em seus títulos, um dos descritores. A descrição dos grupos apresenta um panorama geográfico, histórico e institucional. Essas etapas permitiram identificar os pesquisadores líderes. Assim, optou-se pela utilização da Plataforma Lattes para a identificação de suas produções em seus currículos. A fase de interpretação se dedicou à 
leitura e análise da temática deficiência presente nos artigos selecionados. As categorias de análise na fase interpretativa desta metassíntese foram: 1) Perspectivas teóricas, e 2) Métodos.

A interpretação, propriamente dita, foi precedida da seguinte catalogação: a referência completa do artigo (título, autores/as, revista, temáticas e ano de publicação); o resumo, objetivos, perspectiva teórica, método (tipo, procedimentos). As proposições de Bardin (2009) foram importantes na pré-análise, por meio da leitura flutuante dos trabalhos, que apreenderamse às temáticas transversais à deficiência. Na leitura aprofundada se buscaram as semelhanças, as diferenças, as lacunas, os avanços indicados, as quais se apresentam na sequência.

\section{Resultados e discussão}

Com os critérios definidos, obtiveram-se três 3 grupos de Psicologia. Percebe-se na Tabela 1, com os seguintes itens: título, instituição, líderes pesquisadores, ano de criação e status dos grupos de pesquisa. Observa-se assim, que os primeiros grupos de pesquisa foram criados em uma mesma instituição e ano, e que o grupo de pesquisa mais atual em outra instituição e ano, ambos criados em instituições federais e na região Sudeste. Os primeiros grupos de pesquisa foram excluídos, e o mais atual está certificado.

Tabela 1 - Descrição dos dados referentes aos 3 grupos de Psicologia

\begin{tabular}{|c|c|c|c|c|c|}
\hline Título & Instituição & $\begin{array}{c}\text { Líderes } \\
\text { pesquisadores }\end{array}$ & Região & $\begin{array}{l}\text { Ano de } \\
\text { criação }\end{array}$ & Status \\
\hline $\begin{array}{l}\text { "Desenvolvimento e } \\
\text { deficiência: uma } \\
\text { compreensão } \\
\text { winnicottiana" }\end{array}$ & $\begin{array}{l}\text { Universidade de } \\
\text { São Paulo (USP) }\end{array}$ & $\begin{array}{l}\text { Maria Lúcia Toledo } \\
\text { de Morais } \\
\text { Amirilian; Andrea } \\
\text { Perosa Saigh Jurdi }\end{array}$ & Sudeste & 2002 & Excluído \\
\hline $\begin{array}{l}\text { "Lide - Laboratório } \\
\text { interuridades de } \\
\text { estudos sobre } \\
\text { deficiência" }\end{array}$ & $\begin{array}{l}\text { Universidade de } \\
\text { São Paulo (USP) }\end{array}$ & $\begin{array}{c}\text { Maria Lúcia Toledo } \\
\text { de Morais } \\
\text { Amirilian; Marcos } \\
\text { José da Silveira } \\
\text { Mazzota }\end{array}$ & Sudeste & 2002 & Excluído \\
\hline $\begin{array}{l}\text { "GEPDI - Grupo de } \\
\text { estudos e pesquisa } \\
\text { em deficiência e } \\
\text { inclusão" }\end{array}$ & $\begin{array}{c}\text { Universidade } \\
\text { Estadual Paulista } \\
\text { Júlio de Mesquita } \\
\text { Filho (Unesp) }\end{array}$ & $\begin{array}{l}\text { Lúcia Pereira Leite; } \\
\text { Sandra Eli Sartoreto } \\
\text { de Oliveira Martins }\end{array}$ & Sudeste & 2012 & Certificado \\
\hline
\end{tabular}

Fonte: Elaborado pelas autoras

As áreas de investigação e de intervenção dos pesquisadores, na atualidade, de acordo com as informações disponibilizadas pelos líderes pesquisadores, em seus respectivos Currículo Lattes, estão configuradas na relação entre os campos de saber da Psicologia e da Educação. A seguir, apresenta-se, brevemente, a formação dos líderes, conforme a ordem cronológica de 
criação dos Grupos de Pesquisa em ordem cronológica de formação de seus Grupos de Pesquisa. Amirilian é doutora na área de Psicologia Clínica, pela Universidade de São Paulo, em 1992. Seus estudos se vinculam à Psicologia do Desenvolvimento e à Psicanálise de Winnicott. Jurdi é doutora na área de Psicologia Escolar e do Desenvolvimento Humano, pela Universidade de São Paulo, em 2009. Seus estudos enfatizam os seguintes temas: saúde mental infantil, inclusão escolar, atividade lúdica, desenvolvimento infantil e formação profissional. Mazzotta possui doutorado em Educação, pela Universidade de São Paulo, em 1989. Prioriza a Educação Especial e atua com temáticas relacionadas à educação escolar, formação de professores, educação especial, inclusão social e escolar e políticas educacionais.

Leite doutorou-se em 2003, na área de Educação Especial, pela Universidade Estadual Paulista Júlio de Mesquita Filho (Unesp). Estabelece sua interlocução com o campo de conhecimento da Psicologia da Educação, Psicologia Social e Educação, atuando principalmente com os seguintes temas: deficiência, educação especial, educação inclusiva, necessidades educacionais especiais, processos de ensino e aprendizagem, inclusão social e formação continuada. Martins doutorou-se em 2005, em Educação pela Universidade Estadual Paulista Júlio de Mesquita Filho e produz conhecimento nas seguintes áreas: políticas públicas, Educação Especial/Inclusiva, formação de professores, educação superior e surdez.

Do ponto de vista quantitativo, obtiveram-se um total de 121 artigos, com os critérios apontados anteriormente, assim distribuídos: Leite publicou 33 artigos; Martins, 30 artigos; Mazzotta, 28 artigos; Amiralian, 24 artigos e; Jurdi, 6 artigos. Após o refinamento para a identificação de duplicação, em razão de coautorias, a relação com a temática da deficiência, vinculação e/ou interface com a Psicologia, disponibilidade de acesso on-line, foram submetidos à fase interpretativa da metassíntese, 40 artigos, publicados entre os anos de 1991 e 2017. A Figura 1, identifica 19 trabalhos que não evidenciam, explicitamente, a perspectiva teórica adotada; quatro explicitam quatro autores que subsidiaram teoricamente a investigação. Vale ressaltar que a exposição quantitativa dos trabalhos (Figura 1) seguiu um delineamento histórico de data de publicação. 
Figura 1 - Dados referentes às perspectivas teóricas e temáticas dos artigos

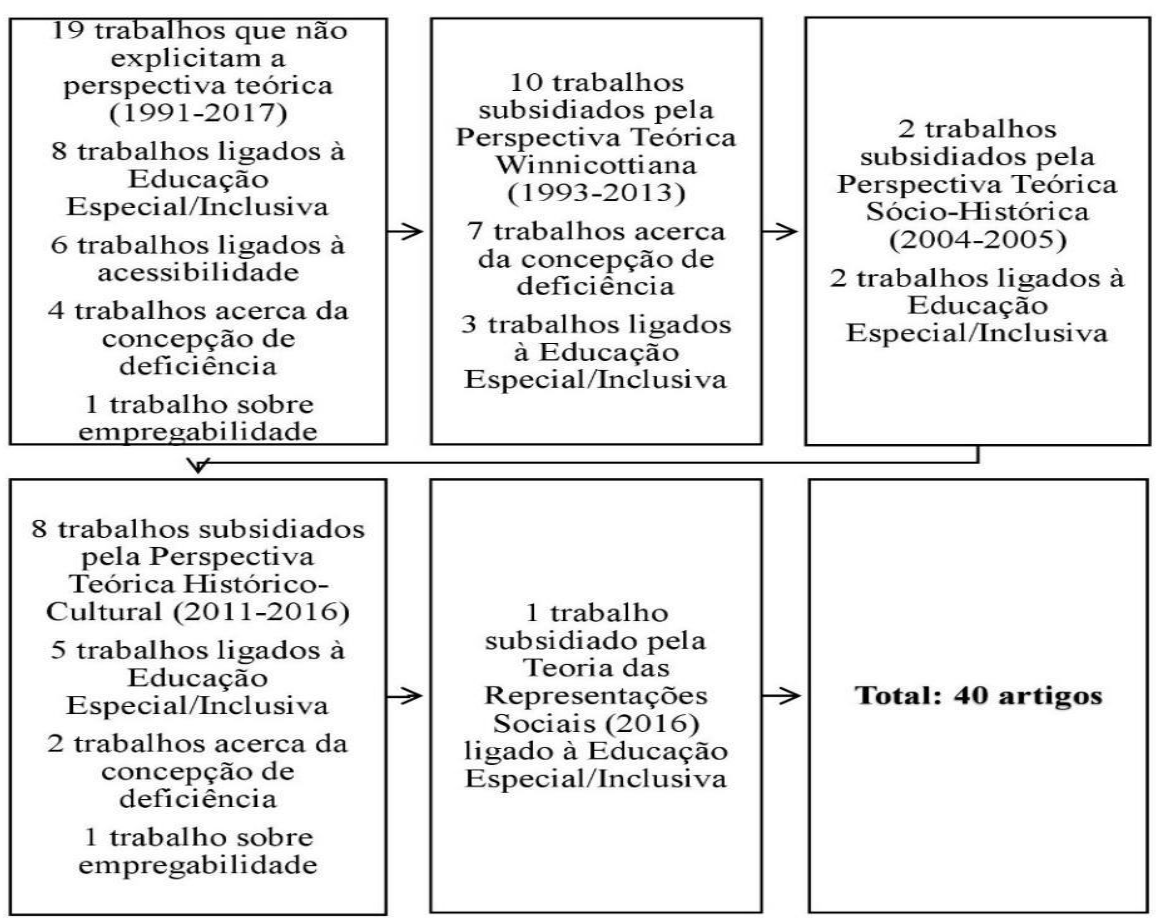

*Há o quantitativo total sobre a perspectiva teórica utilizada ou não nos estudos em cada quadrado $(19,10,2,8$ e 1), totalizando 40 trabalhos, e especificamos em cada um as suas devidas temáticas abordadas, apresentando os quantitativos parciais.

Fonte: Elaborado pelas autoras

Observa-se a relevância da Perspectiva Teórica Winnicottiana em 10 trabalhos. São estudos vinculados ao Grupo de Pesquisa "Desenvolvimento e deficiência: uma compreensão winnicottiana" e Grupo de Pesquisa "Lide - Laboratório interunidades de estudos sobre deficiência". Se faz presente ainda, explicitamente nos artigos, a Perspectiva da Psicologia Histórico-Cultural em oito artigos e a Sócio-Histórica em dois trabalhos, pertencentes ao Grupo de Pesquisa "GEPDI - Grupo de estudos e pesquisa em deficiência e inclusão" e a Perspectiva Teórica das Representações Sociais em um trabalho. Os autores delineiam em seus artigos o percurso histórico e conceitual da temática deficiência, mesmo aqueles que não explicitam um autor de referência. Assim, pode-se asseverar que é fundamental a construção histórica do conceito, com seu percurso datado e situado historicamente. Os artigos refletem as transformações ocorridas na temática deficiência. Por exemplo, no estudo de Amirilian, Becker e Kovács (1991), identifica-se o uso do termo “pessoas portadoras de deficiência” que era usual no início da década de 1990.

O mesmo uso pode ser identificado no artigo de Violante e Leite (2011), sob a Perspectiva Teórica Histórico-Cultural. Talvez isso ocorra em função das normativas 
circulantes da década de 1990 e início dos anos 2000 fazerem uso do termo 'portador', algo já superado nos documentos mais atuais da legislação brasileira.

Além disso, as autoras Amirilian, Becker e Kovács (1991) direcionaram novos olhares para aperfeiçoar, o curso de formação dos futuros profissionais de Psicologia da Universidade de São Paulo (USP), com o objetivo de prepará-los para atuarem junto às pessoas com deficiência. Nesse sentido, podemos perceber o início de um movimento de transformação, nas propostas curriculares dos cursos de Psicologia, justificado pelas autoras, em razão do surgimento de novas demandas de atuação junto às pessoas com deficiência, na década de 1990 . Fatos a serem observados até hoje nas diretrizes dos cursos de Psicologia no atendimento direto ou indireto às pessoas com deficiência, nos mais variados âmbitos - clínico, educacional, organizacional, saúde, dentre outros. Adicionado às questões do movimento de transformação conceitual e de proposição curricular, notamos ainda, que Amirilian et al. (2000) inauguram a discussão de conceitos de deficiência, incapacidade e desvantagem, subsidiada pelo documento do Secretariado Nacional de Reabilitação, da Organização Mundial da Saúde (OMS), denominado com a Classificação Internacional de deficiências, incapacidades e desvantagens: um manual de classificação das consequências das doenças (CIDID), que foi publicado em 1989

Na esteira da discussão teórica, datada historicamente, o estudo de Amirilian (2003), retoma os estudos desenvolvidos na década de 1970, pela psicanalista americana Fraiberg, e seu grupo de pesquisa da Universidade de Ann Harbor, os quais foram utilizados como referenciais teóricos no início das pesquisas, sobre a temática deficiência no Brasil. Nessa direção, outro dado histórico observado, refere-se ao estudo de Amirilian (2004), em que a autora discute as dificuldades afetivo-emocionais das pessoas, com baixa visão. Nesse artigo, a autora enfatiza que, a partir da década de 1970, a área da Saúde, Educação e Tecnologia desenvolveram pesquisas com questões relacionadas à baixa visão. A contribuição da autora circunscreve-se à área da Psicologia e à compreensão das questões afetivo-emocionais das pessoas com baixa visão.

No que tange ao método explicitado nos artigos, 11 não apresentam. Por outro lado, 29 artigos indicam o método adotado na pesquisa. Sendo 6 de Amirilian e de Jurdi, ambas, líder e vice-líder, do Grupo de Pesquisa "Desenvolvimento e deficiência: uma compreensão winnicottiana" publicados, em coautoria, com outros autores, 1 artigo do vice-líder Mazzotta, do Grupo de Pesquisa "Lide - Laboratório interunidades de estudos sobre deficiência" em coautoria, e 22 trabalhos de autoria da líder Leite, vice-líder Martins, do Grupo de Pesquisa 
"GEPDI - Grupo de estudos e pesquisa em deficiência e inclusão" em coautoria com outros autores, destacam o método e procedimentos utilizados.

Pode-se afirmar que os estudos realizados nos grupos de pesquisa, na temática deficiência, analisados, são subsidiados pelo método qualitativo. Destaca-se que os estudos ligados ao Grupo de Pesquisa "Desenvolvimento e deficiência: uma compreensão winnicottiana", em sua maioria apresentam relatos de experiência, e estudos de casos. Utilizam como procedimento metodológico, as entrevistas, a observação e o desenho-estória.

No que se refere aos participantes dos estudos, principalmente, são crianças e, por vezes, adultos, como o estudo de Jurdi e Amirilian (2006), que descreve um relato de experiência de intervenção, realizada no horário de recreio, de uma escola estadual, de ensino fundamental, da cidade de São Paulo - SP, uma vez por semana, durante quatro meses, por duas discentes do quarto ano do curso de graduação em Terapia Ocupacional da Universidade de São Paulo. A proposta de intervenção se refere às atividades lúdicas (jogo de queimada, jogo "alerta" e "corre cotia') entre os 103 estudantes de classe especial e regular da escola, com o objetivo de verificar possíveis modificações nas relações entre os estudantes com e sem deficiência, no espaço escolar.

De acordo com as autoras, "O primeiro procedimento refere-se à observação do cotidiano escolar. Nessa abordagem, a observação ocupa lugar privilegiado, pois é utilizada como principal método de investigação" (JURDI; AMIRILIAN, 2006, p. 196). Ademais, realizaram levantamento com os estudantes, denominado como entrevistas informais para conhecer as brincadeiras, como percebiam as diferenças na escola, e optaram por filmar o recreio. As autoras perceberam a importância do ambiente lúdico como um instrumento que pode potencializar o processo de inclusão de estudantes com deficiência no espaço escolar.

Amirilian (2011) descreve quatro atendimentos de casos de jovens, com baixa visão, em que denomina Caso 1, Caso 2, Caso 3 e Caso 4. Quanto ao Caso 1, a autora, explicita sobre o atendimento de Carla, uma jovem de 15 anos de idade em que busca saber sobre sua escolha profissional e, assim "foi utilizado o Procedimento de Desenhos-Estórias para melhor compreensão da dinâmica que apresenta no momento"' (AMIRILIAN, 2011, p. 25). No Caso 2, sobre o atendimento de Luisa, uma jovem de 13 anos de idade que apresentava dificuldades de aprendizagem, também "Nesse atendimento, o Procedimento de Desenhos Estórias foi utilizado como psicoterapia breve" (AMIRILIAN, 2011, p. 26). No Caso 3, trata-se do atendimento de Maria, uma jovem de 16 anos de idade, que assim como Carla tem dificuldades em escolher sua profissão. Nessa direção, novamente os Desenhos-Estórias fizeram parte da 
sessão. Por fim, no Caso 4, sobre o atendimento de Luís, trata-se de um jovem de 16 anos de idade em que sua mãe procura apoio profissional por não saber lidar com ele.

Souza, Jurdi e Cipullo (2016) apresentam as representações sociais de três professores auxiliares, de nove escolas da rede municipal de ensino fundamental, do município de Santos SP, acerca dos estudantes com deficiência e seu processo de inclusão escolar. Segundo os autores, seis professores aceitaram participar da pesquisa, no período de março a novembro de 2014, mas, no artigo, optaram por apresentar as representações sociais de três professores nos resultados e discussão.

Em relação aos procedimentos metodológicos, Souza, Jurdi e Cipullo (2016, p. 58) afirmam que:

Foram realizadas seis entrevistas semiestruturadas com professores auxiliares de classe de escolas e regiões distintas da cidade de Santos. [...] buscamos trabalhar com uma metodologia capaz de propiciar um espaço confortável e favorável para que os professores pudessem se expressar livremente.

Além disso, Souza, Jurdi e Cipullo (2016) utilizam como instrumento de pesquis,a uma adaptação do "Desenho-Estória". O estudo ligado ao Grupo de Pesquisa "Lide - Laboratório interunidades de estudos sobre deficiência" também utiliza-se de método qualitativo e, da pesquisa de campo, onde realiza uma entrevista semiestruturada, e a aplicação de um questionário. Os participantes do estudo presente no artigo analisado, eram adultos. Aciem e Mazzotta (2013) apresentam um estudo sobre a autonomia pessoal e social de pessoas com deficiência visual (cegueira). Participaram deste estudo 12 pessoas, sendo 6 pessoas com deficiência visual (cegueira), 3 possuíam deficiência visual adquirida e 3 tinham deficiência visual congênita, 4 pessoas eram do sexo masculino e 2 eram do sexo feminino, e 6 familiares dessas pessoas, 3 eram mães, 1 irmão, 1 esposa e outro, o irmão de religião.

Além disso, Aciem e Mazzotta (2013) pontuam que dos familiares entrevistados, uma era pessoa com deficiência visual, e os participantes com deficiência visual (cegueira), são egressos da Unidade para Reabilitação de Deficientes Visuais (URDV), entre os anos de 2002 a 2009. A idade varia entre 30 e 50 anos. Os autores indicam que "O tipo de pesquisa foi qualitativa, onde o pesquisador valorizou as situações que se manifestam em contato direto com o objeto do estudo" (ACIEM; MAZZOTTA, 2013, p. 263). No que concerne aos procedimentos metodológicos, foram utilizadas entrevistas semiestruturadas, com os participantes do estudo e, um questionário foi aplicado.

Por fim, os estudos ligados ao Grupo de Pesquisa “GEPDI - Grupo de estudos e pesquisa em deficiência e inclusão", assim como os outros grupos, também utilizam o método 
qualitativo, por exemplo, Lopes e Leite (2015) apresentam um estudo sobre o conjunto de significações, acerca da deficiência e Polícia Militar para policiais, com deficiência adquirida. Os participantes da pesquisa foram 7 policiais militares, que apresentavam algum tipo de deficiência, sendo 6 da reserva por terem adquirido uma deficiência, e um policial da ativa. As autoras afirmam que os policiais integravam a Associação de Policiais Militares Portadores de Deficiência do Estado de São Paulo (APMDFESP).

No que concerne aos procedimentos metodológicos do estudo, Lopes e Leite (2015, p. 670) descrevem que "A coleta de dados foi realizada por intermédio de entrevistas individuais com o uso do relato oral autobiográfico. As memórias relatadas nas narrativas autobiográficas são construções individuais, todavia, de modo semelhante, coletivas e sociais". Também afirmam que foi solicitado o preenchimento de um questionário de identificação sobre a idade, o estado civil, a patente e ano de ingresso dos participantes na corporação. Logo após, contassem suas histórias. Acerca da análise dos dados, as autoras identificaram três núcleos: “(a) a expressão do trabalho como atividade fundamental; (b) condições de existência: transformações após a deficiência adquirida; (c) condições de existência: relações de suporte social" (LOPE; LEITE, 2015, p. 671).

Leite e Mattos (2016) apresentam um estudo sobre as concepções de deficiência de funcionários e estudantes de uma universidade pública brasileira. Conforme as autoras, participaram desse estudo 2330 pessoas, sendo 1472 estudantes de graduação e 374 de pósgraduação. Quanto à formação dos participantes e as áreas do saber, 207 estudantes matriculados no doutorado, 163 no mestrado e 4 no mestrado profissional, sendo de três 114 grandes áreas (humanas, biológicas e sociais). Ademais, participaram 252 docentes e 232 técnicos-administrativos.

Durante a coleta de dados foi utilizado um instrumento, denominado Escala Concepções de Deficiência (ECD). Há 20 afirmativas referentes a quatro diversas concepções de deficiência como: social, biológica, metafísica e histórico-cultural por meio de 5 sentenças para cada concepção. Além do mais, as autoras destacam que os dados foram coletados, no final do segundo semestre, do ano letivo de 2013, através do envio on-line da escala, e um formulário com informações gerais (curso, ano de ingresso, idade, sexo, faculdade e unidade universitária) dos participantes, para 32 unidades universitárias (LEITE; MATTOS, 2016).

No que se refere aos procedimentos de análise de dados, Leite e Mattos (2016), utilizaram o pacote estatístico do IBM SPSS Statistics Base, em que foram desenvolvidas análises descritivas dos dados como: cálculo de frequência média, mediana e desvio padrão. Quanto análises estatísticas inferenciais, utilizaram 3 testes como: Teste t de Student para 
avaliar a comparação entre duas médias entre as concepções de deficiência mencionadas anteriormente e gênero, Teste ANOVA para avaliar a comparação entre três ou mais grupos (concepções de deficiência e ano de ingresso para os estudantes, e o Teste $r$ de Pearson para avaliar a correlação entre cada uma das concepções de deficiência e idade dos participantes.

Louzada, Martins e Giroto (2017) apresentam um estudo relacionado à oferta da disciplina Libras. Segundo as autoras, foram coletadas 49 grades curriculares de cursos de licenciatura, por meio do acesso aos sites de 3 instituições de educação superior como: Universidade Estadual Paulista (UNESP), Universidade Federal de São Carlos (UFSCar) e, Universidade Federal de Santa Catarina (UFSC). Também afirmam que "A localização das informações contidas nos documentos citados foi realizada por meio da técnica de busca por radicais, proposto por Mazo (2010), também utilizada nos estudos de Velden e Leite (2013)" (LOUZADA; MARTINS; GIROTO, 2017, p. 870). No que se refere à análise dos dados, utilizaram a análise de conteúdo, conforme Bardin. Assim, identificaram 19 cursos que ofertam disciplinas em atendimento às políticas de educação bilíngue para pessoas com surdez, sendo encontradas 22 disciplinas. As categorias de análise foram ensino de Libras, conteúdos sobre Libras e políticas públicas e fundamentos da educação dos surdos.

Portanto, destaca-se que em sua maioria, os estudos apresentam pesquisas de campo, relatos de experiência, pesquisas bibliográficas e documentais. Quanto aos instrumentos de busca de informações, utilizam entrevistas semiestruturadas, questionários aplicados e respondidos, de modo presencial, por vezes on-line, observação, documentos, e análises estatísticas, através da aplicação de testes. No que se refere à análise das informações, observouse que, em sua maioria, utilizam a técnica proposta por Bardin, e os participantes dos estudos são adultos, na maioria das vezes e, por vezes, crianças. Em síntese, pode-se afirmar que a temática deficiência se destaca pela importância de acompanhamento histórico de produção de seu conceito, pelo uso de referenciais teóricos winnicottianos, histórico-sociais, sóciohistóricos e de representações sociais, pela opção metodológica de estudos qualitativos.

\section{Considerações finais}

Este texto procurou sinalizar a importância das Plataformas On-line na divulgação da produção acadêmica de pesquisadores brasileiros (Lattes) e na organização em grupos de pesquisas (DGP) no CNPq. Pelo uso da ferramenta é possível identificar e mapear pesquisas, pesquisadores, áreas de conhecimento, interlocução institucional, temáticas de estudo, referenciais teóricos e metodológicos, além de contribuir na ampliação de rede de 
pesquisadores. A escrita trouxe à baila os estudos do tipo metassíntese, que no presente artigo, sintetiza a temática deficiência, em artigos publicados pelos líderes pesquisadores, de grupos de pesquisa, em Psicologia nas referidas Plataformas. No campo de interlocução da Psicologia, a Educação é fundamental para se refletir sobre a temática deficiência. As perspectivas teóricas e metodológicas, que subsidiam as pesquisas dos grupos e respectivas publicações de artigos, são de base winnicottiana, sócio-histórica, histórico-cultural e das representações sociais; e as temáticas enfatizam a concepção de deficiência, Educação Especial/Inclusiva, acessibilidade e empregabilidade. $\mathrm{O}$ método privilegia estudos qualitativos e os participantes dos campos de investigação se localizam adultos, e, por vezes, no público infantil. As produções analisadas estabelecem estreita relação e imprimem relevância, nos artigos, reflexões a partir de documentos nacionais e internacionais de garantia de direitos das pessoas com deficiência.

O estudo pode ser ampliado com o uso de novos descritores (Educação Especial/Inclusiva) e a composição da totalidade de grupos e de áreas de conhecimento. Pesquisadores da área da Psicologia podem estar cadastrados na área da Educação, visto a historicidade da temática nessa seara de conhecimento. Ressalta-se ainda, a potencialidade da análise com outros tipos de produção acadêmica (dissertações, teses, projetos de pesquisas e de intervenção), com a totalidade dos pesquisadores e com os resultados dos estudos sobre a temática deficiência. Por fim, vislumbra-se a ampliação das análises, por meio, das informações presentes nas Plataformas da Associação Nacional de Pesquisa e Pós-Graduação em Psicologia (ANPEPP) e da Associação Nacional de Pós-Graduação e Pesquisa em Educação (ANPEd), para ampliar o leque de investigação de um tema tão caro e que ainda necessita de muitas investigações para que pessoas com deficiência possam efetivamente deixarem os contornos da sociedade e serem constituidoras de direitos e deveres como qualquer outro cidadão. Nesse aspecto, os estudos da Psicologia têm contribuído e muito ainda podem fazer para o desenvolvimento de ações de pesquisa que possam impactar nas políticas públicas.

\section{REFERÊNCIAS}

ACIEM, T. M.; MAZZOTTA, M. J. S. Autonomia pessoal e social de pessoas com deficiência visual após reabilitação. Revista Brasileira de Oftalmologia, v. 72, n. 4, p. 261$267,2013$.

AMIRILIAN, M. L. T. Adolescência e deficiência visual: dificuldades e cuidados necessários. Winnicott eprints, v. 6, n. 2, p. 16-33, 2011. Disponível em:

http://pepsic.bvsalud.org/pdf/wep/v6n2/a02.pdf. Acesso em: 19 mai. 2020. 
AMIRILIAN, M. L. T. Deficiências: um novo olhar. Contribuições a partir da psicanálise winnicottiana. Estilos da Clínica, v. 8, n. 15, p. 94-111, 2003.

AMIRILIAN, M. L. T. Sou cego ou enxergo? As questões da baixa visão. Educar, n. 23, p. 15-28, 2004.

AMIRILIAN, M. L. T.; BECKER, E.; KOVÁCS, M. J. A especialização do psicólogo para o atendimento às pessoas portadoras de deficiência. Psicologia-USP, São Paulo, v. 2, n. 1, 121 $124,1991$.

BARDIN, L. Análise de conteúdo. São Paulo: Edições 70, 2009.

BEZERRA, G. F. Inclusão escolar de alunos com deficiência: uma leitura baseada em Pierre Bourdieu. Revista Brasileira de Educação, v. 22, n. 69, 2017. Disponível em: Disponível em:

https://www.scielo.br/scielo.php?pid=S141324782017000200475\&script=sci_abstract\&tlng= pt. Acesso em: 13 out. 2020.

BRASIL. Avanços das políticas públicas para Pessoas com Deficiência. Uma análise a partir das Conferências Nacionais. Secretaria Nacional de Promoção dos Direitos da Pessoa com Deficiência. Secretaria de Direitos Humanos da Presidência da República. $1^{\circ}$ Edição, Brasília, 2012. Disponível em: https://www.gov.br/mdh/pt-br/centrais-de-conteudo/pessoacom-deficiencia/avancos-das-politicas-publicas-para-as-pessoas-com-deficiencia. Acesso em: 13 out. 2020.

BRASIL. Lei n. 13.146, de 06 de julho de 2015. Institui a Lei Brasileira de Inclusão da Pessoa com Deficiência (Estatuto da Pessoa com Deficiência). Brasília: Senado Federal, 07 jul. 2015. Disponível em: http://www.planalto.gov.br/ccivil_03/_ato20152018/2015/lei/113146.htm. Acesso em: 13 out. 2020.

BRASIL. Conselho Nacional de Desenvolvimento Científico e Tecnológico (CNPq). Diretório dos Grupos de Pesquisa no Brasil. Disponível em: http://lattes.cnpq.br/web/dgp/o-que-e/. Acesso em: 17 jul. 2017.

GOMES, A. G.; REZENDE, L. K.; TORTORELLI, M. F. P. Acessibilidade e deficiência: análise de documentos normativos. Cadernos de Pós-Graduação em Distúrbios do Desenvolvimento, v. 10, n. 1, p. 130-137, 2010.

GUADENZI, P.; ORTEGA, F. Problematizando o conceito de deficiência a partir das noções de autonomia e normalidade. Ciência \& Saúde Coletiva, v. 21, n. 10, p. 3061-3070, 2016. Disponível em:

https://www.scielo.br/scielo.php?pid=S141381232016001003061\&script=sci_abstract\&tlng= pt. Acesso em: 13 out. 2020. 
GUZZO, R. S. L. et al. Psicologia e Educação no Brasil: uma visão da história e possibilidades nessa relação. Psicologia: Teoria e Pesquisa, v. 26, p. 131-141, 2010. Disponível em: https://www.scielo.br/scielo.php?script=sci_arttext\&pid=S010237722010000500012. Acesso em: 13 out. 2020.

GUZZO, R. S. L.; RIBEIRO, F. M. Psicologia na Escola: Construção de um horizonte libertador para o desenvolvimento de crianças e jovens. Estudos e Pesquisas em Psicologia, v. 19, n. 1, p. 298-312, 2019. Disponível em: https://www.epublicacoes.uerj.br/index.php/revispsi/article/view/43021/29668. Acesso em: 13 out. 2020.

JURDI, A. P. S.; AMIRILIAN, M. L. T. M. A inclusão escolar de alunos com deficiência mental: uma proposta de intervenção do terapeuta ocupacional no cotidiano escolar. Estudos de Psicologia, v. 23, n. 2, p. 191-202, 2006. Disponível em: https://www.scielo.br/scielo.php?pid=S0103166X2006000200009\&script=sci_abstract\&tlng= pt. Acesso em: 13 out. 2020.

LEITE, L. P.; MATTOS, B. M. Aplicação da escala de concepções de deficiência (ecd) em uma universidade pública do brasil. Journal of Research in Special Educational Needs, v. 16, n. 1, p. 155-158, 2016.

LOPES, E. M. C.; LEITE, L. P. Deficiência adquirida no trabalho em policiais militares: significados e sentidos. Psicologia \& Sociedade, v. 27, n. 3, p. 668-677, 2015. Disponível em: https://www.scielo.br/pdf/psoc/v27n3/1807-0310-psoc-27-03-00668.pdf. Acesso em: 13 out. 2020.

LOUZADA, J. C. A.; MARTINS, S. E. O.; GIROTO, C. R. M. A disciplina Libras na formação de professores: desafios para a formulação de espaços educacionais bilíngues. Práxis Educativa, v. 12, n. 3, p. 864-886, 2017.

MATHEUS, M. C. C. Metassíntese qualitativa: desenvolvimento e contribuições para a prática baseada em evidências. Acta Paulista de Enfermagem, n. 1, p. 543-545, 2009. Disponível em:

https://www.scielo.br/scielo.php?pid=S010321002009000800019\&script=sci_abstract\&tlng= pt. Acesso em: 13 out. 2020.

OLIVEIRA, A. A. S. et al. Metassíntese um método para sistematização de revisões amplas e crítica interna à produção científica. In: CONGRESSO IBERO-AMERICANO

INVESTIGAÇÃO QUALITATIVA, 4., 2015, Aracaju. Anais [...]. Aracaju, SE: Universidade Tiradentes, 2015. p. 147-152.

OLIVEIRA, A. A. S.; BASTOS, J. A. Saúde mental e trabalho: descrição da produção acadêmica no contexto da pós-graduação brasileira. Cadernos de Psicologia Social do Trabalho, v. 17, n. 2, p. 239-254, 2014. Disponível em: http://pepsic.bvsalud.org/scielo.php?script=sci_arttext\&pid=S1516-37172014000300007. Acesso em: 13 out. 2020 .

SILVA JÚNIOR, G. E. Conceito de pessoa com deficiência: permanências e rupturas no processo psicossocial de significação. 2016. 117 f. Dissertação (Mestrado em Psicologia) Universidade Federal de Alagoas, Maceió, 2016. 
SOUZA, M. R. S. B. C.; JURDI, A. S.; CIPULLO, M. A. T. Alunos com deficiência: representações sociais de professores auxiliares da rede de ensino fundamental do município de santos. Revista Diálogos e Perspectivas em Educação Especial, v. 3, n. 2, p. 55-68, 2016. Disponível em:

https://revistas.marilia.unesp.br/index.php/dialogoseperspectivas/article/view/6748. Acesso em: 13 out. 2020.

VIOLANTE, R. R.; LEITE, L. P. A empregabilidade das pessoas com deficiência: uma análise da inclusão social no mercado de trabalho do município de Bauru. Cadernos de Psicologia Social do Trabalho, v. 14, n. 1, p. 73-91, 2011. Disponível em:

http://www.revistas.usp.br/cpst/article/view/25717/27450. Acesso em: 13 out. 2020.

VOSGERAU, D. S. A. R.; ROMANOWSKI, J. P. Estudos de revisão: implicações conceituais e metodológicas. Revista Diálogo Educacional, v. 14, n. 41, p. 165-189, 2014. Disponível em:

https://periodicos.pucpr.br/index.php/dialogoeducacional/article/view/2317/2233. Acesso em: 13 out. 2020.

\section{Como referenciar este artigo}

FERREIRA, R. M.; OLIVEIRA, A. A. S. Temática deficiência em grupos de pesquisa em psicologia do CNPQ. Doxa: Rev. Bras. Psico. e Educ., Araraquara, v. 22, n. 00, p. e021001, 2021. e-ISSN: 2594-8385. DOI: https://doi.org/10.30715/doxa.v22i00.14392

Submissão em: $24 / 10 / 2020$

Revisões requeridas em: 19/03/2021

Aceito em: 28/03/21

Publicado em: 20/04/2021 